\title{
Pattern and determinants of BCG immunisation delays in a sub-Saharan African community
}

\author{
Bolajoko O Olusanya ${ }^{1,2^{*}}$
}

\begin{abstract}
Background: Childhood immunisation is recognised worldwide as an essential component of health systems and an indispensable indicator of quality of care for vaccine-preventable diseases. While performance of immunisation programmes is more commonly measured by coverage, ensuring that every child is immunised at the earliest/ appropriate age is an important public health goal. This study therefore set out to determine the pattern and predictors of Bacille de Calmette-Guérin (BCG) immunisation delays in the first three months of life in a SubSaharan African community where BCG is scheduled at birth in order to facilitate necessary changes in current policy and practices for improved services.
\end{abstract}

Methods: A cross-sectional study in which immunisation delays among infants aged 0-3 months attending community-based BCG clinics in Lagos, Nigeria over a 2-year period from July 2005 to June 2007 were assessed by survival analysis and associated factors determined by multivariable logistic regression. Population attributable risk (PAR) was computed for the predictors of delays.

Results: BCG was delayed beyond three months in 31.6\% of all eligible infants. Of 5171 infants enrolled, 3380 (65.4\%) were immunised within two weeks and a further 1265 (24.5\%) by six weeks. A significantly higher proportion of infants born in hospitals were vaccinated in the first six weeks compared to those born outside hospitals. Undernourishment was predictive of delays beyond 2 and 6 weeks while treated hyperbilirubinaemia was associated with decreased odds for any delays. Lack of antenatal care and multiple gestations were also predictive of delays beyond 6 weeks. Undernourishment was associated with the highest PAR for delays beyond 2 weeks (18.7\%) and 6 weeks (20.8\%).

Conclusions: BCG immunisation is associated with significant delays in this setting and infants at increased risk of delays can be identified and supported early possibly through improved maternal uptake of antenatal care. Combining BCG with subsequent immunisation(s) at 6 weeks for infants who missed the BCG may be considered.

\section{Introduction}

Tuberculosis (TB) caused by the Mycobacterium tuberculosis, is a major disease of great public health concern affecting about 13.7 million people globally [1]. Asia and Africa accounted for $55 \%$ and $31 \%$ of the estimated 9.3 million new cases in 2007 with India, China, Indonesia, Nigeria and South Africa ranking as the top five leading countries worldwide. In fact, 13 of the 15 countries with the highest incidence rates are in Africa led by Nigeria with estimated 460,000 new cases per year [1].

\footnotetext{
* Correspondence: boolusanya@aol.com

'Maternal and Child Health Unit, Department of Community Health and Primary Care, College of Medicine, University of Lagos, Surulere, Lagos, Nigeria
}

(c) 2010 Olusanya; licensee BioMed Central Ltd. This is an Open Access article distributed under the terms of the Creative Commons Attribution License (http://creativecommons.org/licenses/by/2.0), which permits unrestricted use, distribution, and reproduction in any medium, provided the original work is properly cited.
Bacille Calmette-Guérin (BCG) vaccination is highly effective in preventing childhood $\mathrm{TB}$, principally miliary disease and meningitis [2]. BCG immunisation has also been found to be protective of other mycobacterial infections such as leprosy, Buruli ulcer and glandular disease [2]. It is currently one of the most widely administered vaccines in infancy and has been shown to be most cost-effective particularly in low-income countries where TB is endemic [3]. Each year, more than 100 million children are immunised with BCG worldwide [3] and coverage in Africa currently stands at $89 \%$ compared to $16 \%$ in 1980 , similar to the global pattern over the same period [4]. However, the regional or global estimates of coverage hardly reflect the trends accurately in countries with high disease burden. For example, the

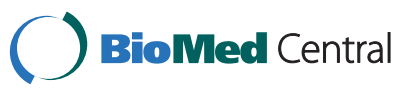


estimated national coverage for Nigeria is currently $69 \%$ up from about 23\% in 1980 [4]. Similarly, national estimates often mask significant variations within each country thus undermining the effectiveness of intervention programmes.

Additionally, there is a growing awareness on the limitation of evaluating the performance of immunisation programmes solely on the basis of coverage irrespective of the age at which immunisation is given as well as the need to establish the pattern and determinants of delays [5-8]. For instance, the current immunisation schedule recommended by the World Health Organisation and widely implemented in developing countries is aimed at providing effective protection at the earliest possible age [9]. Under this schedule, BCG is due at birth or shortly thereafter in order to ensure adequate protection against TB. However, significant delays between the recommended and the actual time of BCG immunisation in a high proportion of infants in developing countries besides the substantial variation in adherence to recommended schedules within and across countries have been reported [8]. Perhaps of greatest concern are delays in immunisations scheduled at birth due to their potential for snowballing into subsequent immunisations with an added risk of outright default [6,10-12]. Such delays are also likely to undermine the effectiveness of immunisation platforms for implementing integrated child health interventions as currently encouraged in developing countries where a high proportion of infants are born outside hospitals $[13,14]$.

Understanding the multi-dimensional determinants of delays is crucial in improving services for routine immunisation in any community [5-7]. For instance, while vaccine shortages or supply-related problems may result in delays in immunisation, the vast majority of reported delays particularly in developing countries are attributable to uptake of services [8]. However, existing evidence on timeliness of BCG immunisation in Africa is limited by sample size, methodology and scope of factors studied $[15,16]$. This community-based study therefore set out to determine the pattern and associated factors for delays in BCG immunisation among infants $\leq 3$ months old in one of the leading contributors to regional and global burden of TB. It was hypothesized that determinants of a 3-month delay in this population was likely to be similar to delays beyond 3 months.

\section{Methods}

\section{Study design and population}

This cross-sectional study is based on a retrospective analysis of a previously reported prospective universal infant hearing screening (UIHS) programme implemented in an inner-city area of Lagos, southwest of Nigeria, with an estimated population of 250,000 [17]. At the time of this study, the community was served by one general hospital, one children's hospital, one specialist maternity hospital and seven primary healthcare centres all of which are State-owned as well as several private hospitals and traditional maternity homes. The study participants consisted of all mother-infant pairs attending four of the seven community-health centres which administered routine BCG immunisation over a twoyear period from July 2005 to June 2007 for which requisite data was available. Under the primary UIHS project, all infants older than three months were not enrolled because of the difficulty of conducting electrophysiological auditory brainstem response screening test in this age group in a community-based setting. At the commencement of this study routine immunisation in the first 3 months in this location consisted of BCG at birth, followed by diphtheria, pertussis and tetanus (DPT)1, at 6 weeks; DPT2, at 10 weeks; and DPT3, at 14 weeks. Oral polio (OPV) and hepatitis B (HB) were subsequently introduced from birth in the course of this study. The uptake for BCG immunisation was typically well over $90 \%$ in most parts of southern Nigeria compared to the national average of $69 \%[18,19]$. The four immunisation clinics chosen accounted for over $75 \%$ of BCG vaccinations in this study location. Ethical approval was obtained from the Lagos State Health Management Board, Nigeria and University College London, UK [17]. Informed consent was obtained from the mothers of all participating infants in writing or by thumb printing.

\section{Study variables}

The primary outcome measure was the age of each infant at the time of visit to the clinic for BCG immunisation. This was determined by difference in the date of visit and the date of birth as reported by the mother. Each child was enrolled on the same day they received the vaccination. The explanatory variables consisted of maternal socio-demographic factors such as age, marital status, ethnicity, religion, education, occupation, spouses' occupation and social class as well as obstetric factors such as parity, antenatal care, place and mode of delivery. Social classes served as proxy for socio-economic status and were determined based on mother's education and father's occupation as previously validated in this population [20]. Social class I was termed as "high", II and III as "middle" and IV or V as "low". Place of delivery consisted of hospitals (public and private) as well as non-hospitals which included traditional maternity homes (usually run by birth attendants without formal professional training), family homes, church premises and before arrival in hospital. Infant factors included gender, gestational age, gestational type (singleton or one of twins/triplets), birth order, history of severe neonatal jaundice (requiring phototherapy and/or exchange blood transfusion), record of illness requiring 
hospital admission before attending BCG clinic and nutritional status. Anthropometric measurements for each child were obtained at the time of enrolment by a trained research worker throughout the study period. Weight was measured with a digital scale (TANITA Baby Scale, Model 1583; Tanita Corporation, Tokyo, Japan). Length was measured supine using graduated polyurethane plastic mats (Child Growth Foundation, London, UK). Gender-specific z-scores for weight-forage (WAZ), body mass index-for-age (BMI) and height/ length-for-age (HAZ) expressed as z-scores were obtained from the World Health Organisation's Multicentre Growth Reference (WHO-MGR) package using the macro provided by the organisation [21]. Moderateto-severe or "significant" wasting, underweight and stunting were defined as zBMI, WAZ and HAZ below -2 respectively. The default settings in the software regarding cut-offs for out-of-range or biologically improbable values were used in the data analysis and all such values were recorded as missing data. Birth weight and length could not be ascertained as birth records of the participants particularly those born outside hospitals were not available in this community-based setting.

\section{Statistical analysis}

In order to determine the degree of delay, the age at immunisation was expressed to the nearest week and categorised into three groups for the purpose of this study. The first group termed "age-appropriate" consisted of infants immunised within the first 2 weeks of birth, making allowance for a grace period of approximately 2 weeks based on the median delay of 2.3 weeks for 45 developing countries recently reported [8]. While all immunisations beyond 2 weeks were considered as delayed, infants who were immunised after 6 weeks were further grouped as "significantly" delayed based on due date for DPT1. The Kaplan-Meier method is an appropriate technique for analysing time-to-event data and was used to quantify the proportion of infants immunised across each specific age. Coverage at age $t$ was estimated by the survival function: $1-S_{K M}(t)$, where $1-S_{K M}(t)$ is the cumulative probability of being immunised by age $t$ [6]. In order to determine the possible impact of place of delivery on coverage, immunisation uptake among infants born in hospitals, traditional maternity homes, family homes and others (church premises or born before arrival) were assessed by the logrank (Mantel-Cox) test. Although requisite individual information on infants older than 3 months who received BCG immunisation was not available, the pattern of delays in the first three months of life was further analysed within the context of the available records from the local health authorities on the total population of infants who received BCG immunisation over the study period.
In establishing the determinants of delays among the enlisted infants in this study, all continuous explanatory variables were first expressed as categorical variables. Thereafter, the bivariate relationship between each explanatory variable and the timing of immunisation was assessed with Pearson's chi-square test. Strength of association between variables was estimated by odds ratios (OR) and the corresponding 95\% confidence intervals (CI). All tests of significance were two-sided. In order to determine predictors for immunisation delays, maternal and infant factors with significance $(\mathrm{p}<0.05)$ in bivariate analyses were considered as eligible for inclusion into two separate multivariable logistic regression models. The first model compared infants immunised by 2 weeks with those immunised after 2 weeks while the second model compared infants immunised by 6 weeks with those immunised after 6 weeks of birth. In each model, non-significant factors $(p \geq 0.05)$ were eliminated by backward stepwise method. Interaction effects of variables in each model were assessed with likelihood ratio test. Crude estimate of model calibration was determined by the Hosmer-Lemeshow test. Population attributable risk (PAR) for each factor in the final model was computed with the formula $\mathrm{Pe}(\mathrm{OR}-1) / \mathrm{OR}$, where $\mathrm{Pe}$ is the percentage of infants with immunisation delays exposed to the factor [22]. SPSS for Windows version 16.0 (SPSS Inc, Chicago, IL, USA) was used for all statistical analyses.

\section{Results}

A total of 5171 mother-infant pairs were enrolled over the study period and represented $68.9 \%$ of all BCG immunised infants (7506) in the first year of life based on records from the local health authorities. Infants rarely presented for BCG immunisation after one year in this population as only $56(0.7 \%)$ were so reported over the entire period of this study and were excluded because BCG is usually not recommended by WHO at this age. Of all immunised infants $\leq 1$ year old, $50.1 \%$ were age-appropriate and $62.9 \%$ were immunised by 6 weeks (Figure 1). Of the 5171 enrolled for this study, delivery in hospitals accounted for $48.6 \%$, traditional maternity homes $39.5 \%$, family homes $6.3 \%$, and others $5.6 \%$. None of the eligible mothers withheld consent to participate in this study. The median age of the infants at enrolment was 11 days (inter-quartile range: 5 - 19 days). In all 3380 (65.4\%) infants were immunised in the first 2 weeks, 1265 (24.5\%) between $2-6$ weeks and $526(10.2 \%)$ after 6 weeks.

The proportion of infants $\leq 3$ months old vaccinated each week across the place of delivery is shown in Figure 2. The log-rank test $(\mathrm{p}=0.029)$ indicated that there were significant variations in the age of immunisation among the four groups of infants based on place of birth when unadjusted for potential confounding factors. 


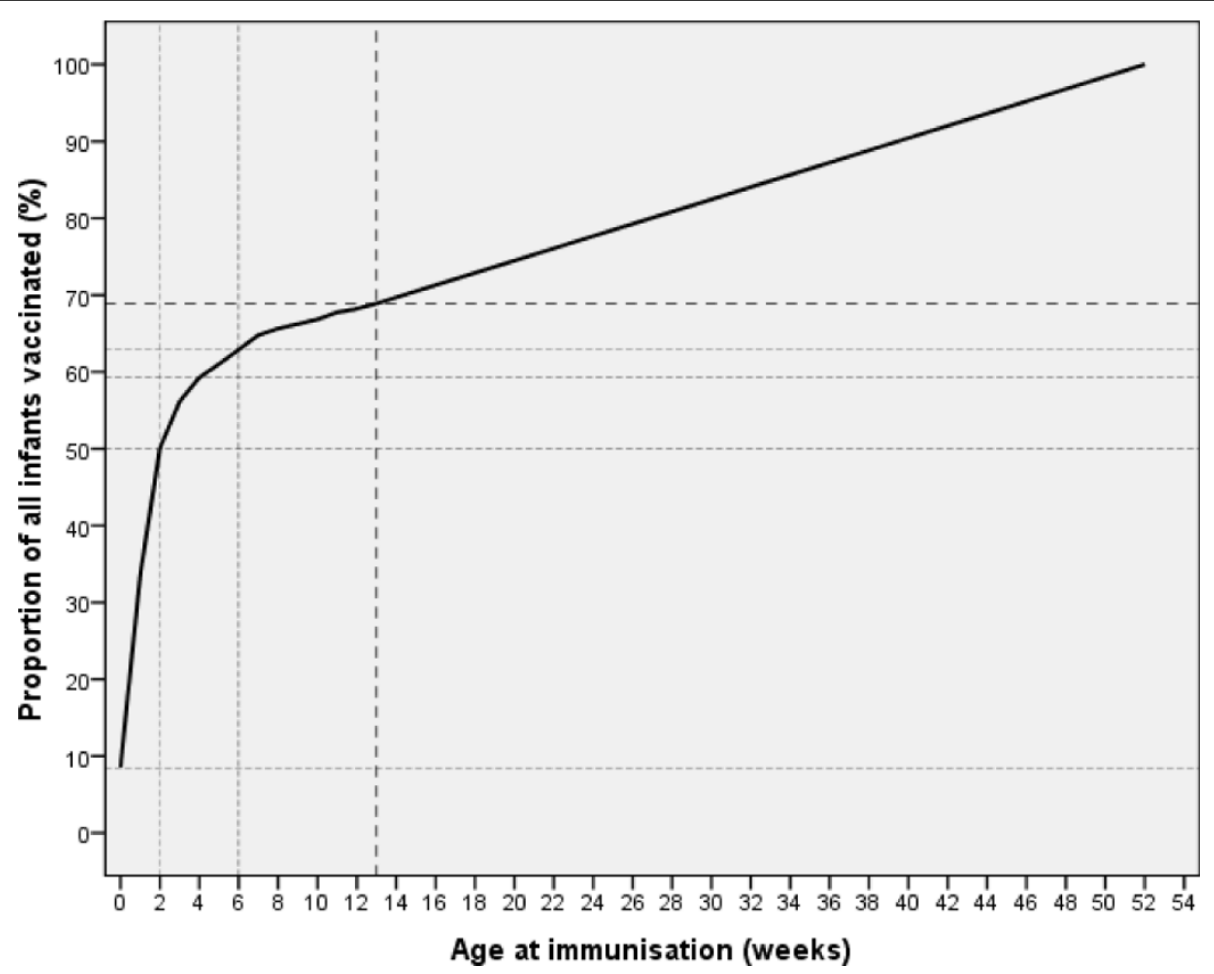

Figure 1 Proportion of all infants aged 0 - 12 months who received BCG immunisation in Lagos, Nigeria $(n=7506)$

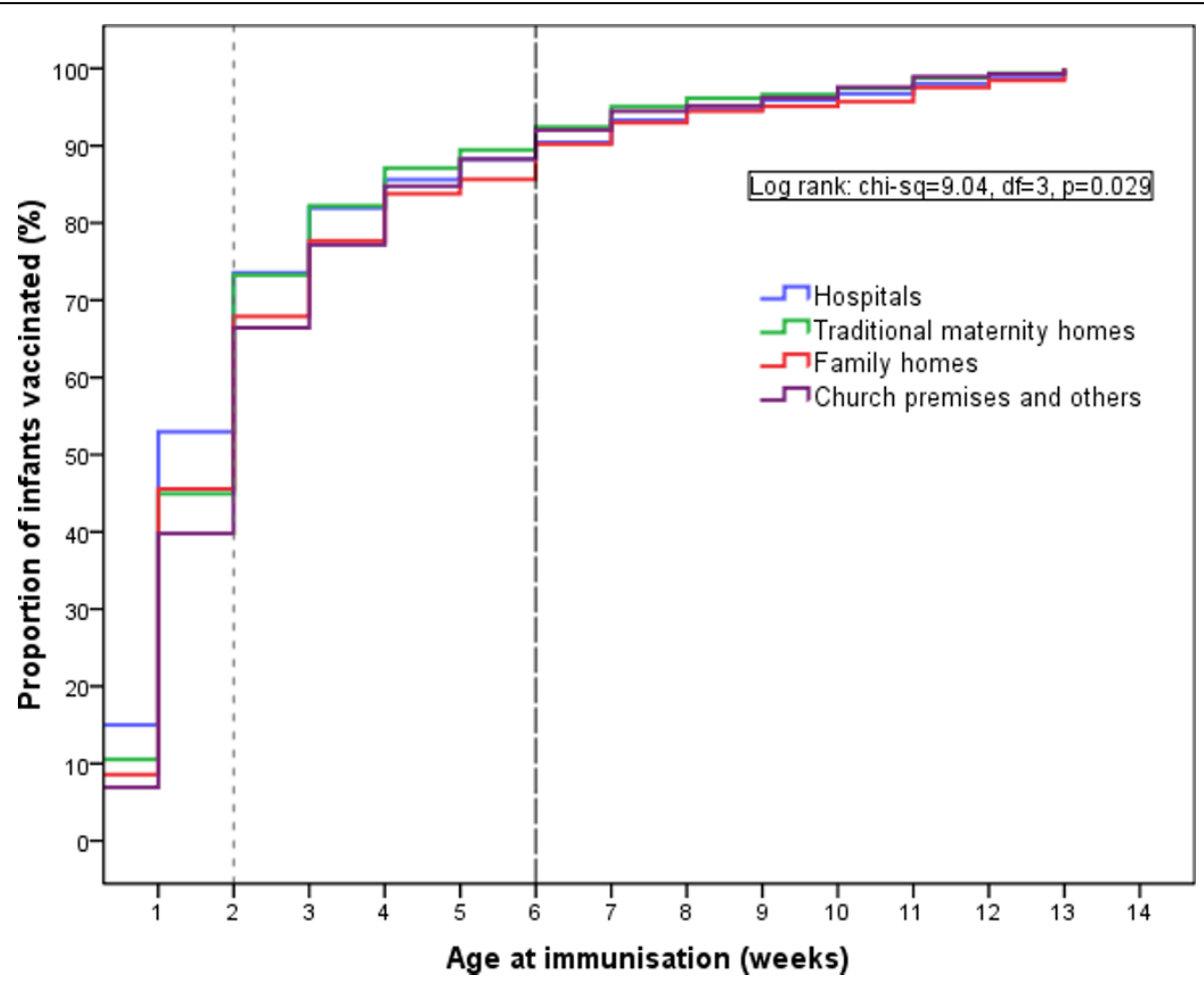

Figure 2 Proportion of infants aged 0 - 3 months that received BCG immunisation in Lagos, Nigeria $(n=5171)$ 
The highest proportion of infants with age-appropriate immunisation was among hospital deliveries and the least proportion came from infants delivered in church premises or before arrival in hospitals. There was a sharp increase from birth till two weeks of age, with at least $65 \%$ coverage regardless of the place of delivery. Using a benchmark of $85 \%$, there was at least 4 weeks delay from birth in this cohort. The longest delay from birth was potentially 52 weeks or 50 weeks from the age-appropriate limit of 2 weeks based on the data from the health authorities.

Maternal and infant characteristics are presented in Tables 1 and 2. Mean age of mothers was $27.93 \pm$ (SD: 5.18 years). As previously reported, the vast majority of mothers belonged to the middle or high social class but over half (51.7\%) delivered outside hospital facilities. More than one-third (39.2\%) had formal full or part time employment and $2.1 \%$ did not attend antenatal care for the current delivery. The vast majority (98.3\%) of the infants were born at term ( $\geq 37$ weeks) and 5.8\% had a history of severe neonatal jaundice. Some one third (37.4\%) were undernourished by at least one measure of nutritional deficit.

In the bivariate analyses, maternal education, occupation, place of delivery, mode of delivery, infant hospitalisation in the first month of life, severe neonatal jaundice and undernourished physical state were significantly associated with delays beyond 14 days but only undernourishment emerged as predictor after multivariable logistic regression with a PAR of $18.7 \%$ (Table 3). Mode of delivery and severe neonatal jaundice were associated with decreased odds for delays. The logistic model did not show any evidence of poor calibration (HosmerLemeshow test: $\chi^{2}=3.16$, df $=5, p=0.676$ ). Similarly, maternal occupation, lack of antenatal care, multiple gestations, preterm birth, severe neonatal jaundice and undernourishment were significantly associated with delays beyond 42 days in the bivariate analyses and all factors except preterm birth were predictive of delays after multivariable logistic regression. Lack of antenatal care, multiple gestations and undernourishment were associated with increased odds for delays while formal employment and severe neonatal jaundice were associated with deceased odds for delays. Undernourishment was also associated with the highest PAR (20.8\%). The logistic model was well calibrated (Hosmer-Lemeshow test: $\chi^{2}=2.26, \mathrm{df}=6, \mathrm{p}=0.894$ ) and no significant interactions were found among the variables included in both logistic regression models.

Additionally, infants with immunisation delays beyond 6 weeks had at least three-fold increased odds of being at risk of sensorineural hearing loss and two-fold increased odds of dropping out of a multi-stage hearing screening programme (data not shown).

\section{Discussion}

A unique feature of this study besides the large sample size compared to similar studies particularly from developing countries is the recruitment of infants at the point of receiving immunisation over an extended period rather than a retrospective audit of clinical records or survey of patient cards $[6,15,16]$. The findings from this study corroborate the existing evidence from both developed and developing countries on the misrepresentation associated with the evaluation of the performance of immunisation programmes solely on the basis of attained coverage. Remaining appropriately immunised in an endemic region like Sub-Saharan Africa lowers the risk of infection and possible disease outbreak. The magnitude of the delays for an immunisation like BCG scheduled for birth is therefore obviously worrisome considering that the observed delays for example could not be justified even on the basis of the revised guidelines for communities where HIV is highly prevalent because HIV-infected infants are usually not symptomatic at birth [23]. Moreover, infants immunised late in this population were not only susceptible to tuberculosis in an environment with beleaguered and poorlyresourced health care systems but were also at substantial risk of delayed protection against other vaccine preventable diseases under subsequent immunisations. In addition, such delays were likely to undermine the effectiveness and attractiveness of BCG immunisation clinics as an alternative platform for conventional hospitalbased newborn screening programmes in communities particularly in Sub-Saharan Africa and South Asia where a high proportion of babies are delivered outside hospitals $[13,24,25]$. Evidently, more attention is warranted to address the determinants of delays for childhood immunisation to optimise the value of the current huge investments on provision of free vaccines in developing countries.

A recent study in South Africa has suggested a possible shift in the timing of BCG from birth to 10 weeks because of the potential for enhanced memory CD4 T cell response in later years [26]. But the available evidence is too limited to justify a revision of the current national immunisation schedule in Africa or other developing countries in the immediate future. Combining BCG with DPT1 at 6 weeks for those who missed BCG would appear as one approach to improve coverage and minimise the snowballing effects with subsequent immunisations $[6,12]$. However, this practice was not common in the current study location primarily for logistical reasons except on national immunisation days when opportunities were provided for any missed immunisations. It may therefore be necessary to seek ways of eliminating or minimising the existing 
Table 1 Maternal characteristics and timing of infants aged 0-3 months attending BCG immunisation clinics

\begin{tabular}{|c|c|c|c|c|}
\hline \multirow[t]{2}{*}{ Maternal factors } & \multirow{2}{*}{$\frac{\text { Total }}{n=5171}$} & \multicolumn{3}{|c|}{ Timing of BCG immunisation } \\
\hline & & $\begin{array}{l}1-14 \text { days } \\
n=3380\end{array}$ & $\begin{array}{l}15-42 \text { days } \\
n=1265\end{array}$ & $\begin{array}{l}\text { After } \\
42 \text { days } \\
n=526\end{array}$ \\
\hline \multicolumn{5}{|l|}{ Age $\left(\right.$ Years) ${ }^{a}$} \\
\hline$<20$ & 173 & $118(68.2)$ & $42(24.3)$ & $13(7.5)$ \\
\hline $20-35$ & 4538 & $2972(65.5)$ & $1109(24.4)$ & $457(10.1)$ \\
\hline$>35$ & 448 & $281(62.7)$ & $111(24.8)$ & $56(12.5)$ \\
\hline \multicolumn{5}{|l|}{ Marital status } \\
\hline Married & 5001 & $3272(65.4)$ & $1214(24.3)$ & $515(10.3)$ \\
\hline Not married & 170 & $108(63.5)$ & $51(30.0)$ & $11(6.5)$ \\
\hline \multicolumn{5}{|l|}{ Ethnicity } \\
\hline Non-Yoruba & 519 & $341(65.7)$ & $113(21.8)$ & $65(12.5)$ \\
\hline Yoruba & 4652 & $3039(65.3)$ & $1152(24.8)$ & $461(9.9)$ \\
\hline \multicolumn{5}{|l|}{ Religion } \\
\hline Muslim & 3418 & $2230(65.2)$ & $859(25.1)$ & $329(9.6)$ \\
\hline Christianity & 1753 & $1150(65.6)$ & $406(23.2)$ & $197(11.2)$ \\
\hline \multicolumn{5}{|l|}{ Education } \\
\hline None & 145 & $78(53.8)$ & 49 (33.8) & $18(12.4)$ \\
\hline Primary/Secondary & 4191 & $2735(65.3)$ & $1041(24.8)$ & $415(9.9)$ \\
\hline Post-secondary & 835 & $567(67.9)$ & $175(21.0)$ & $93(11.1)$ \\
\hline \multicolumn{5}{|l|}{ Occupation } \\
\hline None & 709 & $476(67.1)$ & $146(20.6)$ & $87(12.3)$ \\
\hline Small/petty trade & 2436 & $1518(62.3)$ & $656(26.9)$ & $262(10.8)$ \\
\hline Formal employment & 2026 & $1386(68.4)$ & $463(22.9)$ & $177(8.7)$ \\
\hline \multicolumn{5}{|l|}{ Social class } \\
\hline High & 340 & $231(67.9)$ & $67(19.7)$ & $42(12.4)$ \\
\hline Middle & 4010 & $2624(65.4)$ & $994(24.8)$ & $392(9.8)$ \\
\hline Low & 821 & $525(63.9)$ & $204(24.8)$ & $92(11.2)$ \\
\hline \multicolumn{5}{|l|}{ Parity } \\
\hline 1 & 2139 & $1421(66.4)$ & $491(23.0)$ & $227(10.6)$ \\
\hline $2-4$ & 2827 & $1842(65.2)$ & $715(25.3)$ & $270(9.6)$ \\
\hline$>4$ & 205 & $117(57.1)$ & $59(28.8)$ & $29(14.1)$ \\
\hline \multicolumn{5}{|l|}{ Antenatal care } \\
\hline One or more visits & 5061 & $3314(65.5)$ & $1242(24.5)$ & $505(10.0)$ \\
\hline None & 110 & $66(60.0)$ & $23(20.9)$ & $21(19.1)$ \\
\hline \multicolumn{5}{|l|}{ Place of delivery } \\
\hline Hospital & 2513 & $1697(67.5)$ & $545(21.7)$ & $271(10.8)$ \\
\hline Traditional maternity home & 2042 & $1323(64.8)$ & $535(26.2)$ & $184(9.0)$ \\
\hline Family home & 327 & $189(57.8)$ & $97(29.7)$ & $41(12.5)$ \\
\hline Church premises/others & 289 & $171(59.2)$ & $88(30.4)$ & $30(10.4)$ \\
\hline \multicolumn{5}{|l|}{ Mode of delivery } \\
\hline Vaginal & 4902 & $3149(64.2)$ & $1246(25.4)$ & $507(10.3)$ \\
\hline Caesarean & 269 & 231 (85.9) & $19(7.1)$ & $19(7.1)$ \\
\hline
\end{tabular}

${ }^{\mathrm{a}}$ Missing data $=12(0.2 \%)$. 
Table 2 Characteristics and timing of infants aged 0-3 months attending BCG immunisation clinics

\begin{tabular}{|c|c|c|c|c|}
\hline \multirow[t]{2}{*}{ Infant factors } & \multirow{2}{*}{$\begin{array}{l}\text { Total } \\
n=5171\end{array}$} & \multicolumn{3}{|c|}{ Timing of BCG immunisation } \\
\hline & & $\begin{array}{l}1-14 \text { days } \\
n=3380\end{array}$ & $\begin{array}{l}15-42 \text { days } \\
n=1265\end{array}$ & $\begin{array}{l}\text { After } 42 \text { days } \\
\mathrm{n}=526\end{array}$ \\
\hline \multicolumn{5}{|l|}{ Gender } \\
\hline Male & 2669 & $1711(64.1)$ & $677(25.2)$ & $281(10.5)$ \\
\hline Female & 2502 & $1669(66.7)$ & $588(23.5)$ & $245(9.8)$ \\
\hline \multicolumn{5}{|l|}{ Gestational age $\mathrm{e}^{\mathrm{a}}$} \\
\hline Full term & 5083 & $3326(65.4)$ & $1249(24.6)$ & $508(10.0)$ \\
\hline Preterm & 81 & $53(65.4)$ & $14(17.3)$ & $14(17.3)$ \\
\hline \multicolumn{5}{|l|}{ Gestational type } \\
\hline Singleton & 5077 & $3324(65.5)$ & $1244(24.5)$ & $509(10.0)$ \\
\hline One of twins/triplets & 94 & $56(59.6)$ & $21(22.3)$ & $17(18.1)$ \\
\hline \multicolumn{5}{|l|}{ Birth order } \\
\hline First child & 2139 & $1421(66.4)$ & $491(23.0)$ & $227(10.6)$ \\
\hline Second child or other & 3032 & $1959(64.6)$ & $774(25.5)$ & $299(9.9)$ \\
\hline \multicolumn{5}{|l|}{ Neonatal jaundice } \\
\hline None & 4873 & $3158(64.8)$ & $1200(24.6)$ & $515(10.6)$ \\
\hline Yes & 298 & $222(74.5)$ & $65(21.8)$ & $11(3.7)$ \\
\hline \multicolumn{5}{|c|}{ Hospitalisation for other illness } \\
\hline No & 4939 & $3179(64.4)$ & $1251(25.3)$ & 509 (10.3) \\
\hline Yes & 232 & $201(86.6)$ & $14(6.0)$ & $17(7.3)$ \\
\hline \multicolumn{5}{|l|}{ Nutritional status ${ }^{\mathrm{b}}$} \\
\hline Not undernourished & 3219 & $2247(69.8)$ & 705 (21.9) & $267(8.3)$ \\
\hline Undernourished* & 1933 & $1122(58.0)$ & $555(28.7)$ & $256(13.2)$ \\
\hline
\end{tabular}

Missing data: $7(0.1 \%)^{\mathrm{a}}, 19(0.4 \%)^{\mathrm{b}}$. *Any undernourished physical state based on z-scores for weight-for-age, height/length-for-age or body-mass-index of less than -2 singly or in combination, using WHO 2006 Growth Standards. ${ }^{21}$

infrastructural barriers to simultaneous immunisation for infants who missed BCG when DPT1 is administered.

Direct comparison of delays in this study with similar studies in the literature was somehow hampered by the variations in the age profile of the subjects and the expanded scope beyond BCG immunisation. Perhaps the most relevant study of interest is the recent report by Clark and Sanderson [8]. For instance, while it was not possible to determine the median delay for the entire population of infants who received BCG in this community, the median delay among the study participants of 2 weeks compared favourably with the estimate of 2.3 weeks for developing countries or 2.7 weeks for Nigeria. In addition, the age-specific coverage showed substantial improvements over the reported national rates for Nigeria [8]. For example, BCG coverage at 4 weeks and 12 weeks was $59 \%$ and $68 \%$ respectively compared to the reported national estimates of $27 \%$ and $41 \%$. One possible reason for these differences is that the current study was conducted in southern Nigeria where uptake of childhood immunisation is substantially higher than in northern Nigeria [27]. There are several ongoing initiatives supported by prominent developmental agencies to improve the immunisation rates in northern Nigeria and evidence such as provided by this study underscores the need to emphasise improved timelines in uptake besides the overall coverage.

Some of the prominent risk factors in this study are rarely reported possibly because of the younger age profile and method of recruitment for this study compared with similar studies $[5,6,8,15,28,29]$. For instance, the protective effect of treated neonatal hyperbilirubinaemia is unlikely to be detected or of interest in studies among older infants. A possible explanation for the finding in this study is that mothers of infants who had received phototherapy or exchange blood transfusion were likely to be jolted by such an early experience of a potentially fatal/disabling illness to promptly embrace any recommended protective measure against future illness or 
Table 3 Predictors of BCG immunisation delays after multivariable logistic regression analyses

\begin{tabular}{|c|c|c|c|c|}
\hline \multirow[t]{2}{*}{ Factors } & \multicolumn{2}{|c|}{ Delays beyond 14 days } & \multicolumn{2}{|c|}{ Delays beyond 42 days } \\
\hline & $\begin{array}{c}\text { Adjusted }^{\mathrm{a}} \text { odds ratio } \\
\text { (95\% Confidence } \\
\text { interval) }\end{array}$ & $\begin{array}{c}\text { Population attributable risk } \\
(\%)\end{array}$ & $\begin{array}{c}\text { Adjusted }{ }^{\mathrm{b}} \text { odds ratio } \\
\text { (95\% Confidence } \\
\text { interval) }\end{array}$ & $\begin{array}{c}\text { Population } \\
\text { attributable } \\
\text { risk (\%) } \\
\end{array}$ \\
\hline \multicolumn{5}{|l|}{ Maternal } \\
\hline Employed (regular or part-time) & - & - & $0.68(0.51-0.89)^{* *}$ & 0 \\
\hline $\begin{array}{l}\text { No antenatal care(current } \\
\text { delivery) }\end{array}$ & - & - & $2.27(1.37-3.75)^{* * *}$ & 2.2 \\
\hline $\begin{array}{l}\text { Delivery by caesarean section } \\
\text { Infant }\end{array}$ & $0.29(0.20-0.42)^{* * *}$ & 0 & - & - \\
\hline Multiple gestations & - & - & $1.85(1.07-3.19)^{*}$ & 1.5 \\
\hline Treated for neonatal jaundice & $0.55(0.42-0.72)^{* * *}$ & 0 & $0.28(0.15-0.52)^{* * *}$ & 0 \\
\hline Undernourished $^{c}$ & $1.70(1.45-2.09)^{* * *}$ & 18.7 & $1.74(1.45-2.09)^{* * *}$ & 20.8 \\
\hline
\end{tabular}

${ }^{a}$ Adjusted for maternal education, occupation, place of delivery, hospital admission and other covariates.

${ }^{\mathrm{b}}$ Adjusted for place of delivery, preterm birth and other covariates. ${ }^{\mathrm{C}}$ Based on z-scores for weight-for-age, height/length-for-age or body-mass-index of less than -2 singly or in combination, using WHO 2006 Growth Standards. ${ }^{21}{ }^{*} \mathrm{p}<0.05$; ${ }^{* *} \mathrm{p}<0.01$; ${ }^{* *} \mathrm{p}<0.001$

infection. This may in fact also explain why this factor was a consistent predictor of BCG immunisation timeliness in the first three months of life. Perhaps more notable is the consistent predictive utility of an infant's nutritional status for BCG immunisation delays which accords with available limited reports from other resource-poor countries on default among older infants $[30,31]$. Since nutritional status is often a more powerful index of socio-economic status than social class the finding in this study thus appears to be consistent with studies that have established family income status/poverty as predictors of immunisation delays in developed and developing countries $[5,15,28,32]$. The findings on hyperbilirubinaemia and any undernourished physical state as consistent predictors of delays in the first three months of life therefore seems to validate the a priori hypothesis that these factors were likely to remain significant in older infants. For instance, one study from Brazil suggested similar immunogenicity of BCG vaccine in term infants aged 0-6 months with and without intrauterine growth restriction [33]. Moreover, the effects of undernutrition are likely to become more pronounced in late infancy and early childhood particularly due to poverty induced protein-energy deficiencies. However, the exact relationship between nutritional status and immunisation delays from early infancy merits further investigation considering the high burden of childhood undernutrition in this region [25]. In addressing this problem, it may be helpful for instance to ascertain if the delay for an undernourished child is attributable to parental decision and/ or an advice from health workers.

Lack of antenatal care is an established index of poor maternal health-seeking behaviour with diverse adverse perinatal outcomes. The associated delay with immunisation has been previously reported $[32,34,35]$ and in fact not unexpected as antenatal clinics are the conventional platforms for educating pregnant women on the benefits of childhood immunisation. Mothers who did attend antenatal clinics were unlikely to use nutritional supplements which are freely provided as part of antenatal care in this population. This factor along with lack of counselling on proper infant feeding practices may underpin the observed association between infant's undernourishment and immunisation delays. Although it made intuitive sense to expect delays associated with lack of antenatal care to be greater among multiparous women or those who delivered outside hospitals, no such evidence was found when interactions among these terms were tested. A possible reason could be due to the lack of details on the actual number of antenatal visits made to allow for a more robust multi-level testing for the other variables. For example, the infants whose mothers received the WHO recommended minimum of four antenatal visits were significantly more likely to be associated with improved immunisation uptake than those with less than four visits [35]. It was also not unlikely that the increased risk of delays among infants with multiple gestations who were usually underweight was attributable to the common practice of keeping such infants at home until they appeared strong enough (with added weight) to be presented at public places like immunisation clinics. The decreased odds associated with caesarean delivery (predominantly non-elective) compared to normal/vaginal delivery would suggest that affected mothers are more likely to embrace postnatal services such as immunisation following the extended post delivery contact with hospital services. Mothers with formal employment are more likely to take advantage of the statutory 12 weeks maternity leave before its expiration to obtain BCG immunisation for their children as this may be difficult once they returned to work. 
Although place of birth was associated with delays in the bivariate analyses in line with the significant difference observed in the survival analysis, this factor was not predictive of delays after adjusting for other confounding variables. A similar pattern was reported in one study from Malawi [29] while another from China found home birth to be independently predictive of immunisation delays [28]. It is not uncommon for birth order to be associated with immunisation delays $[6,7,28,34,35]$ but no such evidence was found in this study in line with some other studies [29].

Notwithstanding the strengths and uniqueness of this study, the extent to which the findings can be generalised to the rest of the country and other communities in subSaharan Africa appears uncertain considering some additional limitations of the study. For example, it was difficult to estimate the number of infants who were not taken to the immunisation clinics in the community due to the lack of vital registration data from the local health authority. Where such data exist it may then be worthwhile to explore the possibility of a tracking system based on mobile phone which is now commonly used in many urban areas to detect and follow up defaulting mothers through text messages. Selection bias was not improbable as this study was limited to four of the seven BCG clinics in the community even though they potentially accounted for $75 \%$ of all BCG immunisation. The study design also precluded comparison with other immunisations scheduled within the first three months while no detailed information was available on infants older than 3 months regardless of their immunisation status. In addition, parents and the health workers were not interviewed to ascertain possible reasons for delays or default such as illness of the mother/child and other unavoidable constraints as well as the potential contribution of service-related factors such as rescheduling due to vaccine shortage, waiting time and convenience of visits. Nonetheless, this study has further demonstrated the need to pay attention to timeliness of reported immunisation coverage in evaluating the performance of BCG immunisation. It has also highlighted important but modifiable predictors and early markers of childhood immunisation delays in this region that will facilitate improved services for routine BCG immunisation and forestall potential snowballing of delays to subsequent immunisation in early childhood. Improved uptake of antenatal care should provide a platform for supporting mothers early to address some of these factors.

\section{Abbreviations}

BCG: Bacille Calmette-Guérin; DPT: Diphtheria, Pertussis and Tetanus; PAR: Population Attributable Risk; UIHS: Universal Infant Hearing Screening.

\section{Acknowledgements}

The support of Linda Luxon and Sheila Wirz of the Institute of Child Health, University College London, UK on the substantive project that preceded this post-doctoral work is acknowledged. The author is also grateful for the kind support received from all the health workers and mothers at centres that participated in this study as well as the dedication of the field workers for this project.

\section{Author details}

${ }^{1}$ Maternal and Child Health Unit, Department of Community Health and Primary Care, College of Medicine, University of Lagos, Surulere, Lagos, Nigeria. ${ }^{2}$ Affiliation during study period: Institute of Child Health, University College London, 30 Guilford Street, London WC1N IEH, UK.

\section{Competing interests}

The author declares that they have no competing interests.

Received: 20 October 2009

Accepted: 20 January 2010 Published: 20 January 2010

\section{References}

1. World Health Organisation: Global Tuberculosis Control 2009. Epidemiology, Strategy, Financing. Geneva 2009.

2. Fine PEM, Carneiro AM, Milstein JB, Clements JC: Issues relating to the use of BCG in immunisation programmes. A discussion document. Geneva. World Health Organisation 1999.

3. Trunz BB, Fine PEM, Dye C: Effect of BCG vaccination on childhood tuberculous meningitis and miliary tuberculosis worldwide: a metaanalysis and assessment of cost-effectiveness. Lancet 2006, 367:11731180.

4. World Health Organisation/UNICEF: Estimates of national immunisation coverage 1980-2008.http://www.who.int/immunization_monitoring/ routine/immunization_coverage/en/index4.html, (accessed October 15, 2009).

5. Dombkowski KJ, Lantz PM, Freed GL: Risk factors for delay in ageappropriate vaccination. Public Health Rep 2004, 119:144-155.

6. Dayan GH, Shaw KM, Baughman AL, Orellana LC, Forlenza R, Ellis A, Chaui J, Kaplan S, Strebel P: Assessment of delay in age-appropriate vaccination using survival analysis. Am J Epidemiol 2006, 163:561-170.

7. Akmatov MK, Kretzschmar M, Krämer A, Mikolajczyk RT: Timeliness of vaccination and its effects on fraction of vaccinated population. Vaccine 2008, 26:3805-3811.

8. Clark A, Sanderson C: Timing of children's vaccinations in 45 low-income and middle-income countries: an analysis of survey data. Lancet 2009, 373:1543-1549.

9. World Health Organisation: State of the world's vaccines and immunisations. Geneva, Switzerland: World Health Organisation 2002http:// www.who.int/vaccines-documents/DocsPDF02/www718.pdf, (accessed October 15, 2009)

10. Yusuf HR, Daniels D, Smith P, Coronado V, Rodewald L: Association between administration of hepatitis $B$ vaccine at birth and completion of the hepatitis $B$ and 4:3:1:3 vaccine series. JAMA 2000, 284:978-983.

11. Guerra FA: Delays in immunisation have potentially serious health consequences. Paediatr Drugs 2007, 9:143-148.

12. Luman ET, Chu SY: When and why children fall behind with vaccinations: missed visits and missed opportunities at milestone ages. Am J Prev Med 2009, 36:105-111.

13. World Health Organisation/United Nations Children's Fund: Global Immunisation Vision and Strategy (GIVS), 2006-2015. Geneva/New York 2005http://www.who.int/vaccines-documents/DocsPDF05/GIVS_Final_EN. pdf, (Accessed October 15, 2009).

14. World Health Organisation: Strategic Framework for Integrating Additional Child Survival Interventions with Immunization in the African Region. Report of a workshop in Harare, 2-5 World Health Organization, WHO/AFRO 2005http://www.afro.who.int/measles/intergration/ african_regional_strategic_framework.pdf, (Accessed October 15, 2009).

15. Tadesse H, Deribew A, Woldie M: Predictors of defaulting from completion of child immunization in south Ethiopia, May 2008: a case control study. BMC Public Health 2009, 9:150. 
16. Sadoh AE, Eregie CO: Timeliness and completion rate of immunization among Nigerian children attending a clinic-based immunization service. J Health Popul Nutr 2009, 27:391-395.

17. Olusanya $\mathrm{BO}$, Ebuehi $\mathrm{OM}$, Somefun $\mathrm{AO}$ : Universal infant hearing screening programme in a community with predominant non-hospital births: a three-year experience. J Epidemiol Community Health 2009, 63:481-487.

18. Oladokun RE, Lawoyin TO, Adedokun BO: Immunization status and its determinants among children of female traders in Ibadan, SouthWestern Nigeria. Afr J Med Med Sci 2009, 38:9-15.

19. Odusanya OO, Alufohai JE, Meurice FP, Clemens R, Ahonkhai VI: Short term evaluation of a rural immunization program in Nigeria. $J$ Natl Med Assoc 2003, 95:175-9.

20. Olusanya O, Okpere E, Ezimokhai M: The importance of social class in voluntary fertility. West Afr J Med 1985, 4:205-212.

21. World Health Organisation: WHO Anthro 2005 software and macros for SPSS. Geneva: WHO 2006.

22. Rockhill B, Newman B, Weinberg C: Use and misuse of population attributable fractions. Am J Public Health 1998, 88:15-19.

23. Hesseling AC, Cotton MF, Fordham von Reyn C, Graham SM, Gie RP Hussey GD: Consensus statement on the revised World Health Organization recommendations for BCG vaccination in HIV-infected infants. Int J Tuberc Lung Dis 2008, 12:1376-1379.

24. Olusanya BO: Optimising the use of BCG immunisation clinics for early childhood development in developing countries. Vaccine 2009, 27:37193723.

25. United Nations Children's Fund (UNICEF): The state of the world's children 2009. Maternal and newborn health. New York, USA 2008, 125-129.

26. Kagina BM, Abel B, Bowmaker M, Scriba TJ, Gelderbloem S, Smit E, Erasmus M, Nene N, Walzl G, Black G, Hussey GD, Hesseling AC, Hanekom WA: Delaying BCG vaccination from birth to 10 weeks of age may result in an enhanced memory CD4 T cell response. Vaccine 2009, 27:5488-5495

27. National Population Commission (NPC) [Nigeria] and ORC Macro: Nigeria Demographic and Health Survey 2003 Calverton, Maryland: National Population Commission and ORC Macro 2004, 128-131.

28. Cui FQ, Gofin R: Immunization coverage and its determinants in children aged 12-23 months in Gansu, China. Vaccine 2007, 25:664-671.

29. Jahn A, Floyd S, Mwinuka V, Mwafilaso J, Mwagomba D, Mkisi RE, Katsulukuta A, Khunga A, Crampin AC, Branson K, McGrath N, Fine PE: Ascertainment of childhood vaccination histories in northern Malawi. Trop Med Int Health 2008, 13:129-138.

30. Iqbal Hossain M, Yasmin R, Kabir I: Nutritional and immunisation status, weaning practices and socio-economic conditions of under five children in three villages of Bangladesh. Indian J Public Health 1999, 43:37-41.

31. Zondag AM, Nouwen $\mathrm{J}$, Voorhoeve HW: Immunisation and nutritional status of under-fives in rural Zambia. Cent Afr J Med 1992, 38:62-66.

32. Bates AS, Wolinsky FD: Personal, financial and structural barriers to immunization in socioeconomically disadvantaged urban children. Pediatrics 1998, 101:591-596.

33. Mussi-Pinhata MM, Goncalves AL, Foss NT: BCG vaccination of full-term infants with chronic intrauterine malnutrition: influence of immunization age on development of post-vaccination, delayed tuberculin hypersensitivity. Bull World Health Organ 1993, 71:41-48.

34. Babalola S, Lawan U: Factors predicting BCG immunization status in northern Nigeria: a behavioral-ecological perspective. J Child Health Care 2009, 13:46-62.

35. Bondy JN, Thind A, Koval JJ, Speechley KN: Identifying the determinants of childhood immunization in the Philippines. Vaccine 2009, 27:169-75.

doi:10.1186/1478-4505-8-1

Cite this article as: Olusanya: Pattern and determinants of BCG

immunisation delays in a sub-Saharan African community. Health

Research Policy and Systems 2010 8:1.

Publish with Bio Med Central and every scientist can read your work free of charge

"BioMed Central will be the most significant development for disseminating the results of biomedical research in our lifetime. "

Sir Paul Nurse, Cancer Research UK

Your research papers will be:

- available free of charge to the entire biomedical community

- peer reviewed and published immediately upon acceptance

- cited in PubMed and archived on PubMed Central

- yours - you keep the copyright 